Check for updates

Cite this: RSC Adv., 2017, 7, 53658

Received 3rd August 2017

Accepted 13th November 2017

DOI: $10.1039 / c 7 r a 08588$ e

rsc.li/rsc-advances

\title{
Cyanocobalamin conjugates of cisplatin and diaminocyclohexane-platinum(II): matrix-assisted laser desorption ionization mass spectrometry characterization using 4-chloro- $\alpha$-cyanocinnamic acid as the matrix $\dagger$
}

\author{
G. Ventura, ${ }^{a}$ F. Arnesano, (D) ab C. D. Calvano, (D) ab F. Palmisano ${ }^{\text {ab }}$ \\ and T. R. I. Cataldi $(\mathbb{D} * a b$
}

cis-Diamminedichloroplatinum(II), also known as cisplatin, is a widely used chemotherapeutic agent to treat several malignant tumours, but unfortunately it causes serious side effects, especially nausea, vomiting and nephrotoxicity. Enhancing the selectivity to cancer cells using other compounds combined with cisplatin may overcome these issues. Here, cisplatin and oxaliplatin derivatives bearing a cyanocobalamin (CNCbl) unit were prepared and investigated by matrix-assisted laser desorption/ionization (MALDI) mass spectrometry (MS). A 4-chloro- $\alpha$-cyanocinnamic acid (CICCA) matrix was very effective to explore the formation of $\mathrm{CNCbl-Pt(॥)} \mathrm{conjugates.} \mathrm{In} \mathrm{the} \mathrm{case} \mathrm{of} \mathrm{cisplatin,} \mathrm{the} \mathrm{conjugate} \mathrm{is} \mathrm{formed} \mathrm{by} \mathrm{the} \mathrm{elimination}$ of one easily leaving anionic ligand (i.e., $\mathrm{Cl}^{-}$) from the complex, whereas the cyano group (CN) that is axially coordinated to $\mathrm{Co}(\mathrm{III})$ in $\mathrm{CNCbl}(\mathrm{M})$ becomes bound to the $\mathrm{Pt}(\mathrm{II})$ of monochloro cisplatin, thus yielding a heterobimetallic derivative with the most intense peak of the ion cluster at $\mathrm{m} / \mathrm{z} 1619.55$ ([M + cis- $\left.\left.\mathrm{Pt} "\left(\mathrm{NH}_{3}\right)_{2} \mathrm{Cl}\right]^{+}\right)$and an empirical formula of $\left[\mathrm{C}_{63} \mathrm{H}_{94} \mathrm{ClCo}{ }^{I I \prime} \mathrm{N}_{16} \mathrm{O}_{14} \mathrm{PPt}\right]^{\prime \prime}$. Its identity was revealed by tandem MS (CID TOF/ToF) and the subsequent recognition of the most intense product ions. Likewise, the chelating $(1 R, 2 R)-1,2$-diaminocyclohexane $(R, R-\mathrm{DACH})$ non-leaving group ligand of oxaliplatin, in the form of cis-sulfoaquo $R, R-\mathrm{DACH}-\mathrm{Pt}(I)$, produces two different conjugates with CNCbl in MALDI-MS ([M $\left.\left.+\mathrm{Pt}^{\prime \prime}(R, R-\mathrm{DACH})\right]^{+}\right)$at $\mathrm{m} / \mathrm{z} 1663.64$ and 1664.63, both singly-positively charged, with suggested compositions of $\left[\mathrm{C}_{69} \mathrm{H}_{101} \mathrm{Co}^{\prime \prime \prime} \mathrm{N}_{16} \mathrm{O}_{14} \mathrm{PPt}^{\prime \prime}\right]^{+}$and $\left[\mathrm{C}_{69} \mathrm{H}_{102} \mathrm{CO}^{\prime \prime \prime} \mathrm{N}_{16} \mathrm{O}_{14} \mathrm{PPt}^{\prime \prime}\right]^{+}$, respectively. By properly relying on tandem $\mathrm{MS}$ data, it has been possible to propose a detailed description of these two $\mathrm{CNCbl-}$ Pt(॥) drug conjugates. This investigation sets the stage for future MALDI MS studies on platinum anticancer drugs.

\section{Introduction}

Cisplatin, cis-[ $\left.\mathrm{Pt}\left(\mathrm{NH}_{3}\right)_{2} \mathrm{Cl}_{2}\right]$, is a widely recognized anticancer drug normally administered intravenously using saline solutions..$^{1-3}$ The drug interaction with DNA requires the activation of the neutral cisplatin through a series of spontaneous aquation reactions, which involve the sequential replacement of the chloro ligands with water molecules. Its mechanism of action has been linked to its ability to form covalent adducts with purine DNA bases ${ }^{4}$ causing their chemical modification, and subsequently inducing apoptosis in cancer cells. Since the

${ }^{a}$ Dipartimento di Chimica, Università degli Studi di Bari Aldo Moro, via Orabona 4, 70126 Bari, Italy.E-mail: tommaso.cataldi@uniba.it

${ }^{b}$ Centro Interdipartimentale SMART, Università degli Studi di Bari Aldo Moro, via Orabona 4, 70126 Bari, Italy

$\dagger$ Electronic supplementary information (ESI) available. See DOI: $10.1039 / \mathrm{c} 7 \mathrm{ra0} 8588 \mathrm{e}$ discovery of cisplatin, an impressive number of cis- $-\mathrm{PtA}_{2} \mathrm{X}_{2}$ analogues (where $\mathrm{A}$ and $\mathrm{X}$ denote a cis-oriented amine and leaving groups, respectively ${ }^{1,2}$ ) were produced so far in the attempt to develop new platinum drugs. ${ }^{5}$ Indeed, modifications of either the A or X group dramatically change the anticancer activity of such platinum complexes. ${ }^{6,7}$ For instance, the role of the leaving group can be readily appreciated in the case of carboplatin where the monodentate $\mathrm{Cl}^{-}$leaving group of cisplatin is replaced by a bidentate dicarboxylate ligand (cyclobutane dicarboxylic acid) leading to a reduced reactivity, a lower DNA binding kinetics and different cytotoxicity. In oxaliplatin [[(1R,2R)-cyclohexane-1,2-diamine](ethanedioato- $\left.O, O^{\prime}\right)$ platinum(II)]], the two amine ligands are replaced by a bidentate 1,2diaminocyclohexane ligand (for improved antitumor activity) whereas the two $\mathrm{Cl}^{-}$ligands are replaced by a bidentate, oxalate "leaving group" that is responsible for improved water solubility and a different pharmacokinetic profile (oxaliplatin, unlike cisplatin, rapidly undergoes non-enzymatic transformation into 
reactive compounds). ${ }^{7-9}$ Despite its widespread use, the approved Pt anticancer drug family (cisplatin, carboplatin and oxaliplatin) is associated with significant dose-limiting toxicities including nephrotoxicity and neurotoxicity; ${ }^{\mathbf{1 0}}$ poor targeting and the development of resistance are further issues of concern. Consequently, intense research efforts are devoted to developing new strategies for safer and more effective therapy through e.g. cisplatin prodrugs. ${ }^{6,7,11}$

Cobalamin (vitamin $\mathrm{B}_{12}$ ) comprises an octahedral $\mathrm{Co}$ (III) ion in the center of a planar tetra-pyrrole corrin ring having a higher degree of saturation compared with porphyrins and greater flexibility due to an increased number of $\mathrm{sp}^{3}$ carbons. ${ }^{12,13}$ The uptake of vitamin $\mathrm{B}_{12}$ in mammalian cells is mediated by specific, high-affinity receptors that are overexpressed on numerous human tumors. ${ }^{\mathbf{1 4}}$ Interestingly, the affinity of cyanocobalamin $(\mathrm{CNCbl})$ conjugates for the receptors remains high enough; furthermore, rapidly proliferating tumor cells ask for increased supply of nutrients including vitamin $\mathrm{B}_{12} \cdot{ }^{15,16}$ The conjugation of this vitamin with therapeutic drugs and imaging agents (e.g. cobalt radionuclides, Gd(III), nitric oxide, colchicine analogues, etc.) can be explored for targeted delivery into the affected tissues improving tumor selectivity. ${ }^{\mathbf{6}, 16-18}$ Several papers have also appeared specifically concerning the use of vitamin $\mathrm{B}_{12}$ to deliver Pt drugs including cisplatin and its analogues. Alberto's group (Zurich University) first showed that cis$\left[\mathrm{Pt}\left(\mathrm{NH}_{3}\right)_{2} \mathrm{Cl}\left(\mathrm{OH}_{2}\right)\right]^{+}$, the mono-activated form of cisplatin, reacts with vitamin $\mathrm{B}_{12}$ to form a cyanide-bridged CNCbl-cisplatin conjugate whose X-ray structure was solved. ${ }^{15,19-22}$ Several potential prodrugs, sharing a "Co-CN-Pt" motif, were also synthesized and characterized by the same group. ${ }^{20}$ In vitro cytotoxicity and mechanistic aspects of Pt prodrugs were also elucidated. ${ }^{22}$ Evidence was provided that CNCbl-Pt(II) drug conjugates (recognized by intracellular enzymes) are converted to coenzyme $\mathrm{B}_{12}$ in an enzymatic adenosylation assay; reductive adenosylation of the conjugates (i.e. the prodrugs) ultimately leads, to the release of the Pt(II) complexes. Recently, cellular uptake of vitamin $\mathrm{B}_{12}$-cisplatin conjugates was estimated via detection of their metal constituents (Co, Pt, and $\mathrm{Re}$ ) by inductively coupled plasma mass spectrometry (ICP-MS).$^{15}$ To the best of our knowledge, matrix assisted laser desorption ionization mass spectrometry (MALDI MS) has not yet been fully evaluated for the characterization of CNCbl-Pt(II) drug conjugates. Indeed, the only literature finding is reported by Alberto and coworkers $^{19}$ where MALDI-TOF MS, using $\alpha$-cyano-4hydroxycinnamic acid matrix, was employed to corroborate NMR data on the "vitamin $\mathrm{B}_{12}$-cisplatin" conjugate. No mass spectra were provided and, apparently, authors failed to detect the intact conjugate at the expected $\mathrm{m} / \mathrm{z}$ value of 1619 (vide infra), whereas the occurrence of three diagnostic fragment ions was claimed at $m / z 1607[\mathrm{M}-\mathrm{Cl}+\mathrm{Na}]^{+}, m / z 1591\left[\mathrm{M}-\mathrm{Cl}-\mathrm{NH}_{3}+\right.$ $\mathrm{Na}]^{+}$and $m / z 1571\left[\mathrm{M}-\mathrm{Cl}-2 \mathrm{NH}_{3}+\mathrm{Na}\right]^{+}$. Note however that the sodiated adducts cannot be single charged ions and that the proposed assignments are not internally consistent.

The choice of matrix is of paramount importance ${ }^{23}$ especially for highly labile compounds such as CNCbl and (likely) its Pt(II) drug conjugates. It is widely recognized that the most common proton transfer matrices such as $\alpha$-cyano-4-hydroxycinnamic acid (CHCA), para-nitroaniline and 2,5-dihydroxybenzoic acid exhibited an extensive fragmentation of $\mathrm{CNCbl}$ giving rise to a complete decyanation with concomitant formation of [M - CN $+\mathrm{H}]^{+\bullet},[\mathrm{M}-\mathrm{CN}+\mathrm{Na}]^{+\bullet}$ and $[\mathrm{M}-\mathrm{CN}+\mathrm{K}]^{+\bullet} \cdot{ }^{24-26}$ These findings suggest that such matrices are, most likely, useless also for CNCbl-Pt(II) drug conjugates considering that their proposed structure just involves Pt(II) coordination to the cyano group. ${ }^{19}$

As recently demonstrated, ${ }^{26}$ 4-chloro- $\alpha$-cyanocinnamic acid (ClCCA) is up to now the only matrix allowing desorption/ ionization of intact $\mathrm{CNCbl}$ as protonated adduct $[\mathrm{M}+\mathrm{H}]^{+}$; the radical protonated species $[\mathrm{M}-\mathrm{CN}+\mathrm{H}]^{+}$, formed through the facile ${ }^{\circ} \mathrm{CN}$ neutral loss, was anyway observable reflecting the relatively low Co-C bond energy. The possibility of detecting the protonated adduct of intact $\mathrm{CNCbl}$ opens the way for the application of MALDI MS for speciation of $\mathrm{Cbl}$ homologues differing by the nature of the $\beta$-side axial ligand (cyano, methyl, hydroxy and adenosyl) and, as it will be demonstrated in the following, for the characterization of CNCbl-Pt(II) drug (e.g. cisplatin and oxaliplatin) conjugates. MALDI MS could then be fruitfully employed in the wide field of drug-vitamin $B_{12}$ conjugates for both synthetic and clinical applications, an ultimate goal being represented by applications in the emerging field of imaging of platinum drugs/prodrugs and their metabolites in biological tissues. ${ }^{27,28}$

\section{Materials and methods}

\subsection{Chemicals}

Water, acetonitrile, methanol, acetic acid, ethanol, cis-diammineplatinum(II) dichloride, [SP-4-2-(1R-trans)]-(1,2-cyclohexanediamine- $\left.N, N^{\prime}\right)\left[\right.$ ethanedioata $\left.(2-)-O, O^{\prime}\right]$ platinum, 2,5dihydroxybenzoic acid (DHB), $\alpha$-cyano-4-hydroxycinnamic acid (CHCA), 3-(4-chlorophenyl)-2-cyanoacrylic acid also known as 4chloro- $\alpha$-cyanocinnamic acid (ClCCA), para-nitroaniline (PNA) were obtained from Sigma-Aldrich (Milan, Italy). All solvents used were LC-MS grade. Mass standards kit for calibration was purchased from AB Sciex (Ontario, Canada).

\subsection{Instrumentation}

All experiments were performed using a 5800 MALDI ToF/ToF analyzer (AB SCIEX, Darmstadt, Germany) equipped with a neodymium-doped yttrium lithium fluoride (Nd:YLF) laser (345 $\mathrm{nm})$, in reflectron ion mode with a typical mass accuracy of 5 ppm. ${ }^{29}$ In MS and MS/MS mode 1000 laser shots were typically accumulated by a random rastering pattern, at laser pulse rate of 400 and $1000 \mathrm{~Hz}$, respectively; mass spectra shown in the following were accumulated and averaged on five single mass spectra (1000 laser shots each). MS/MS experiments were performed setting a potential difference between the source and the collision cell of $1 \mathrm{kV}$; ambient air was used as the collision gas at a medium pressure of $10^{-6}$ Torr. The delayed extraction (DE) time was set at $350 \mathrm{~ns}$.

DataExplorer software 4.0 (AB Sciex) was used to control the acquisitions and to perform the initial elaboration of data while SigmaPlot 11.0 was used to graph final mass spectra. 
ChemDraw Pro 8.0.3 (CambridgeSoft Corporation, Cambridge, MA, USA) was employed to draw chemical structures.

\subsection{Sample preparation}

All the matrices were prepared at a concentration of $75 \mathrm{mM}$ in $80: 20$ acetonitrile/water. The stock solution of $\mathrm{CNCbl}(7.5 \times$ $10^{-4} \mathrm{M}$ in water) was diluted in ultrapure water as necessary. Stock solutions of $1.0 \mathrm{mg} \mathrm{mL}^{-1}$ of cis-diamminedichloridoplatinum(II) and cis-sulfoaquo $R, R$-DACH-Pt(II) (see ESI, Fig. S1†) were prepared in ultrapure water by dissolving $1 \mathrm{mg}$ of Pt(II) complex in LC-grade water and sonicating for 30 minutes. For the synthesis of the conjugates, $4.0 \mu \mathrm{L}$ of CNCbl stock solution were mixed with $125 \mu \mathrm{L}$ of a platinum compound solution. The resulting mixture was kept under agitation at $60{ }^{\circ} \mathrm{C}$ for $16 \mathrm{~h}$ in $0.5 \mathrm{~mL}$ Eppendorf tubes. For CNCbl-Pt ${ }^{\mathrm{II}}(R, R-$ $\mathrm{DACH})$ mixture, five reaction tubes were examined; after 2, 4, 8, 16 hours the reaction was stopped by placing the solution at $-20{ }^{\circ} \mathrm{C}$. A sample was analyzed immediately after mixing at room temperature $\left(25^{\circ} \mathrm{C}\right)$.

\subsection{MALDI MS analysis}

Unless otherwise specified, a two-step sample preparation process (i.e., matrix in a low-volatile solvent applied on a layer of dried analyte) was used: $1.0 \mu \mathrm{L}$ of sample solution was spotted directly on the target plate and dried in the dark; as a second layer, $1.0 \mu \mathrm{L}$ of matrix was deposited onto the first one, dried in the dark and analysed by MALDI MS.

\section{Results and discussion}

\subsection{MALDI MS of the cyanocobalamin-cisplatin conjugate}

Fig. 1 shows MALDI MS spectra acquired in the positive ion mode of the conjugate formed between $\mathrm{CNCbl}$ and cisplatin. Since the platinum complex is slightly soluble in water, a molar ratio cisplatin/CNCbl $>100: 1$ was reacted in aqueous solution at $60{ }^{\circ} \mathrm{C}$ for $16 \mathrm{~h}$ and the reaction mixture was analyzed by using $\alpha$-cyano-4-hydroxycinnamic acid (CHCA) and 4-chloro- $\alpha$-cyanocinnamic acid (CClCA) as matrices, Fig. 1, plots a and b, respectively. To avoid artefacts, the reacted species were taken from the aqueous solution and deposited on the sample plate without purification. Comparison of plots a and $b$ of Fig. 1 reveals the key role of the MALDI matrix; CHCA affords a main peak at $m / z 1329.57$ due to decyanated and protonated CNCbl molecules (i.e., $[\mathrm{M}-\mathrm{CN}+\mathrm{H}]^{+\bullet}$ ) along with two minor peaks at $m /$ $z 1351.55$ and 1367.53 , which are single-charge sodium and potassium decyanated adducts, $[\mathrm{M}-\mathrm{CN}+\mathrm{Na}]^{+\bullet}$ and $[\mathrm{M}-\mathrm{CN}+$ $\mathrm{K}]^{+\bullet}$, respectively, as previously reported. ${ }^{26}$ No presence of CNCbl-cisplatin conjugate could be seen at the expected $\mathrm{m} / \mathrm{z}$ value of 1619 (see inset of plot a) although, based on previous knowledge $^{19}$ a $16 \mathrm{~h}$ reaction time should be long enough to ensure significant conversion of reactants. Such a finding could be explained by considering the inadequacy of the conventional CHCA proton transfer matrix to desorb/ionize (at least in part) the intact conjugate. As anticipated in the introduction, and extensively discussed in ref. 26, the labile $\mathrm{Co}(\mathrm{III})-\mathrm{CN}$ bond of $\mathrm{CNCbl}$ is homolytically dissociated in the gas phase (reductive

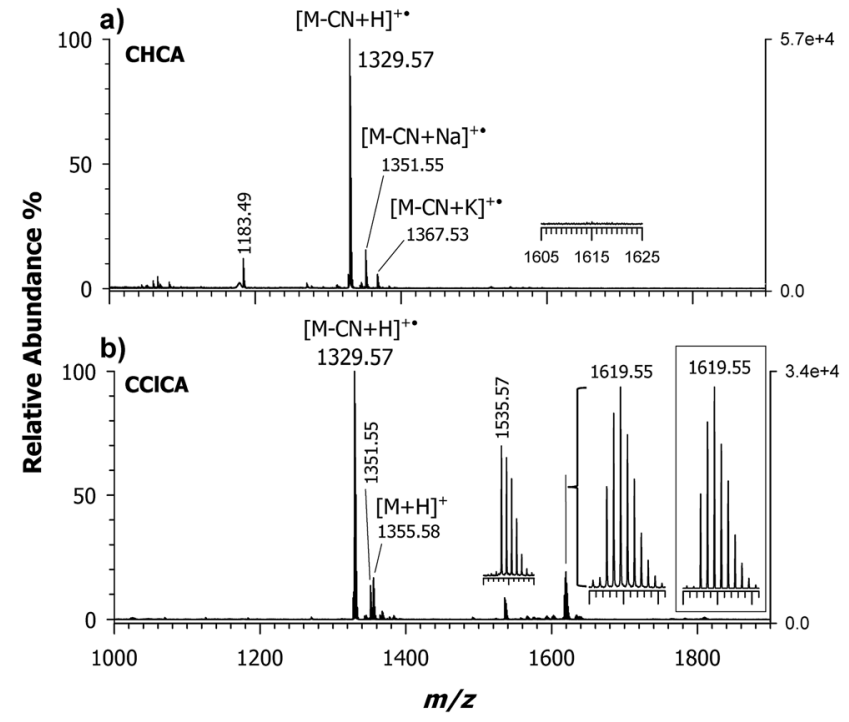

Fig. 1 Positive ion mass spectra by MALDI-ToF of the conjugate between $\mathrm{CNCbl}$ and monochloro cisplatin ([M + cis- $\left.\left.\mathrm{Pt}\left(\mathrm{NH}_{3}\right)_{2} \mathrm{Cl}\right]^{+}\right)$ following the reaction of cis-diamminedichloroplatinum(॥) (cisplatin) with cyanocobalamin in aqueous solution at $60{ }^{\circ} \mathrm{C}$ for $16 \mathrm{~h}$. Spectra obtained using (a) $\alpha$-cyano-4-hydroxycinnamic acid (CHCA) and (b) 4chloro- $\alpha$-cyanocinnamic acid (CCICA) as matrices. The inset shows enlarged isotopic pattern of the ion cluster at $\mathrm{m} / \mathrm{z} 1619.55$ compared with the calculated profile depicted in the rectangle frame. Note the absence of both protonated cyanocobalamin (i.e., $[\mathrm{M}+\mathrm{H}]^{+}$) and adducts with cisplatin in the spectrum collected with CHCA.

decyanation) due to the so called hot character of CHCA. The same effect can be reasonably invoked for an analyte possessing a $\mathrm{Co}(\mathrm{III})-\mathrm{CN}-\mathrm{Pt}(\mathrm{II})$ motif suggesting that an alternative matrix, softer than CHCA, should be able to promote desorbtion/ ionization of the intact molecule. This is indeed verified using a CClCA matrix, as evidenced in plot b of Fig. 1, showing the

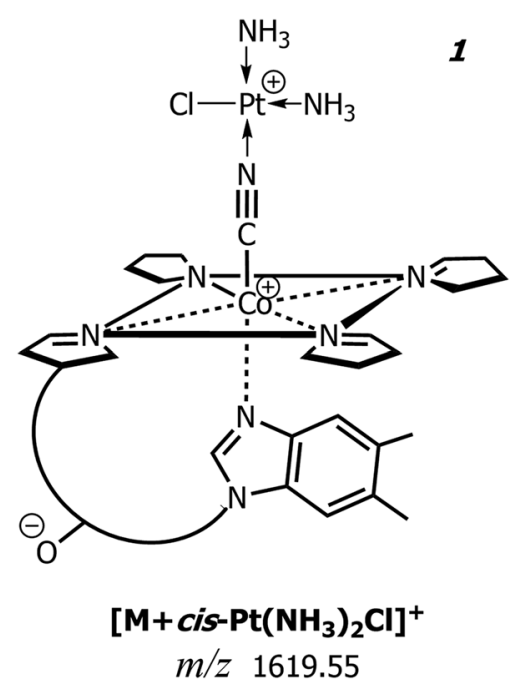

Fig. 2 Schematic structure of the positively charged adduct at $\mathrm{m} / \mathrm{z}$ 1619.55 (1) formed between cyanocobalamin and cisplatin featuring a monochloro-cisplatin, [cis- $\left.\mathrm{Pt}\left(\mathrm{NH}_{3}\right)_{2} \mathrm{Cl}\right]^{+}$. Reagents and conditions: cis- $\mathrm{Pt}\left(\mathrm{NH}_{3}\right)_{2} \mathrm{Cl}_{2}$ and $\mathrm{CNCbl},>100: 1$ molar ratio in water, $16 \mathrm{~h}$ at $60^{\circ} \mathrm{C}$. Acetamide and methyl groups of $\mathrm{CNCbl}$ were omitted for clarity. 


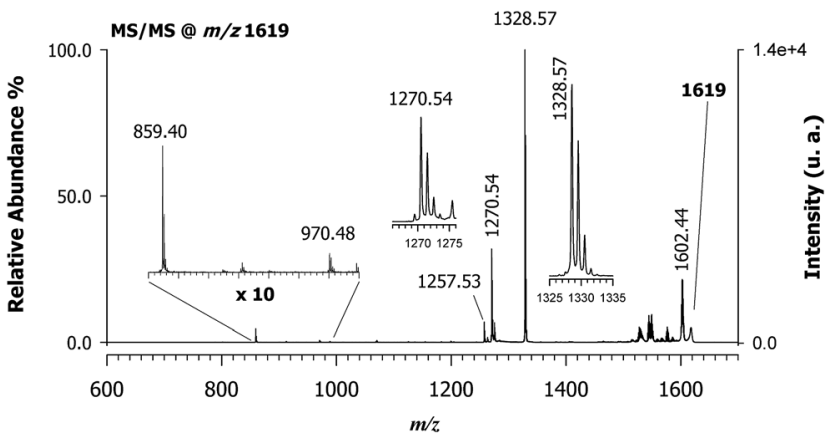

Fig. 3 MALDI-ToF/ToF tandem mass spectra in positive ion mode of cyanocobalamin and monochloro-cisplatin, $\left[\mathrm{M}+\mathrm{Pt}\left(\mathrm{NH}_{3}\right)_{2} \mathrm{Cl}\right]^{+}$, at $\mathrm{m} / \mathrm{z}$ 1619 using CCICA as a matrix; peaks are indicated according to their $\mathrm{m} / \mathrm{z}$ value and their identities as product ions are given in Table 1 . The dominant peak in the spectrum at $m / z 1328.57\left(\left[\mathrm{C}_{62} \mathrm{H}_{88} \mathrm{Co}^{\prime \prime \prime} \mathrm{N}_{13} \mathrm{O}_{14} \mathrm{P}\right]^{+}\right)$ is equivalent to $\mathrm{CNCbl}(\mathrm{M})$ upon the loss of $\mathrm{CN}^{-}$ion. The product ion cluster at $\mathrm{m} / \mathrm{z} 1602.44$ is due to ammonia loss (see also Scheme 1).

occurrence of a base peak at $m / z 1329.57$ (i.e., $[\mathrm{M}-\mathrm{CN}+\mathrm{H}]^{+}$. radical ion), the protonated ion $[\mathrm{M}+\mathrm{H}]^{+}$of intact $\mathrm{CNCbl}$ (at $\mathrm{m} / \mathrm{z}$ 1355.58) and, more importantly, an ion cluster with the most intense signal at $m / z 1619.55$ whose isotopic pattern is shown in the inset. Such $m / z$ value is in very good agreement with that expected for the CNCbl-monochloro cisplatin ([M + cis$\left.\left.\mathrm{Pt}\left(\mathrm{NH}_{3}\right)_{2} \mathrm{Cl}\right]^{+}\right)$conjugate. Apparently, this species is generated by the elimination of one easy-leaving $\mathrm{Cl}^{-}$from the complex, which produces the single and positively charged species; no monoadducts with aqua ligands were observed. To the best of our knowledge, this is the first MALDI MS detection of a conjugate between intact $\mathrm{CNCbl}$ and $\left[\mathrm{Pt}\left(\mathrm{NH}_{3}\right)_{2} \mathrm{Cl}\right]^{+}$.

In Fig. 2 is depicted the suggested schematic structure of this charged conjugate, $\mathbf{1}$, where the central $\mathrm{Co}(\mathrm{III})$ ion of $\mathrm{CNCbl}$ is axially linked to the cyano group whose nitrogen atom is coordinated to $\mathrm{Pt}(\mathrm{II})$ of the monochloro cisplatin. Note that the experimental isotopic pattern compares very well with the chemical composition $\left[\mathrm{C}_{63} \mathrm{H}_{94} \mathrm{ClCo}^{\mathrm{III}} \mathrm{N}_{16} \mathrm{O}_{14} \mathrm{PPt}^{\mathrm{II}}\right]^{+}$of 1 , as illustrated in the inset of Fig. 1b. Most likely, this conjugate encompasses (in the gas-phase) two positively charged sites located on $\mathrm{Co}$ (III) and Pt(II) along with a negatively-charged 5,6dimethylbenzimidazolyl nucleotide phosphate that belongs to the lower $\left(\alpha\right.$-side) axial coordination site. ${ }^{26}$ The suggested structure agrees very well with that described by Alberto and coworkers on the same CNCbl-cisplatin conjugate. ${ }^{19,20,22}$ A second less intense peak is present at $m / z 1535.57$ and because its isotopic pattern does not contain platinum isotopes (vide infra), it is tentatively explained as an adduct between CNCbl and the deprotonated matrix (i.e., 3-(4-chlorophenyl)-2-cyanoacrylate, empirical formula $\left.\mathrm{C}_{10} \mathrm{H}_{5} \mathrm{ClNO}_{2}\right)$, that is $[\mathrm{M}-\mathrm{CN}+\mathrm{H}+$ $\left.\mathrm{C}_{10} \mathrm{H}_{5} \mathrm{ClNO}_{2}\right]^{+}$with monoisotopic mass 1535.5725 Da.

\subsection{MALDI MS/MS of the CNCbl-cisplatin conjugate}

Fig. 3 reports the MALDI MS/MS spectrum of the signal at $\mathrm{m} / \mathrm{z}$ 1619 obtained by high-energy (i.e., $1 \mathrm{kV}$ ) ToF/ToF collisioninduced dissociation tandem mass spectrometry (CID-MS/MS) using CClCA as MALDI matrix. Examination of Fig. 3 shows that there is a very intense (most abundant) monoisotopic peak

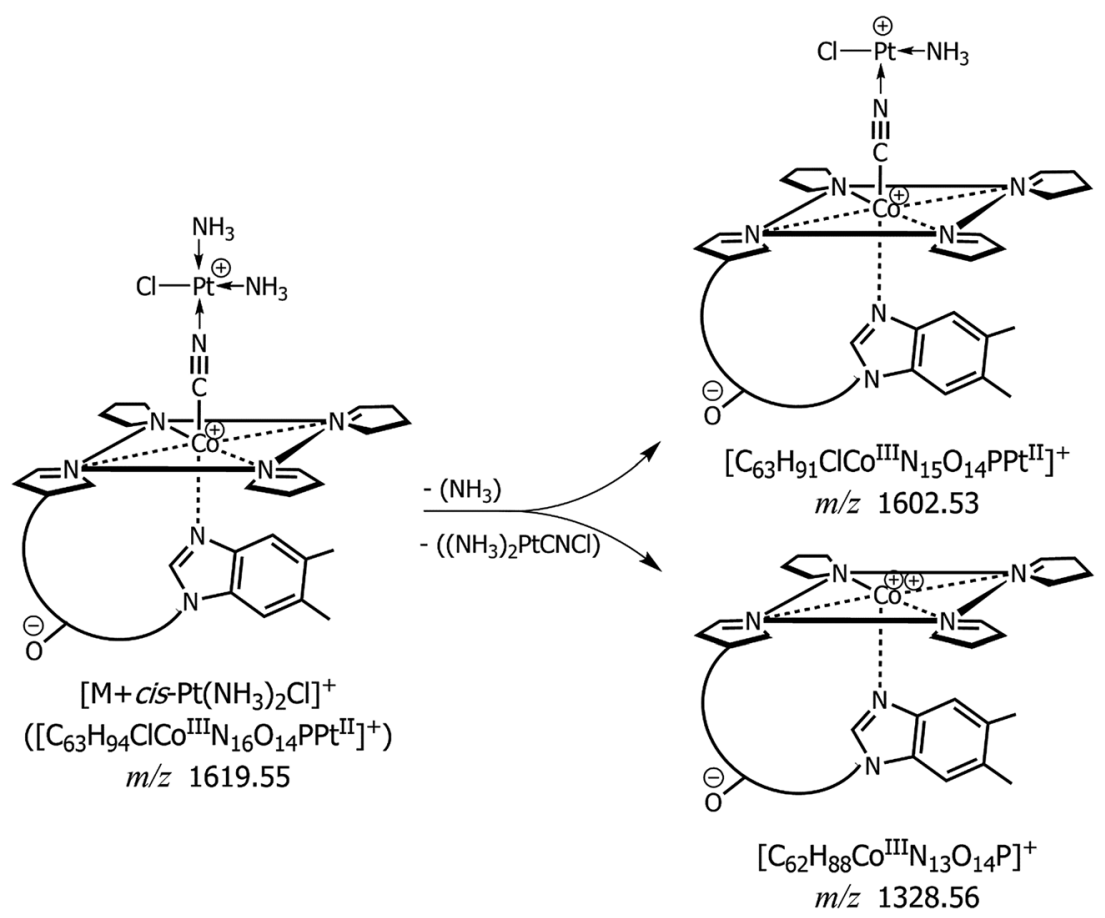

Scheme 1 Proposed fragmentation pathways of the conjugate between $\mathrm{CNCbl}$ (schematic view) and monochloro cisplatin $\left[\mathrm{M}+\mathrm{Pt}\left(\mathrm{NH}_{3}\right)_{2} \mathrm{Cl}\right]^{+}$at $\mathrm{m} / \mathrm{z}$ 1619.55: product ions obtained by MALDI MS/MS with formation of a predominant peak at $\mathrm{m} / \mathrm{z} 1328.56$ along with the neutral loss of $\mathrm{NH}_{3}$ and formation of an ion at $\mathrm{m} / \mathrm{z}$ 1602.53. See MALDI MS/MS spectrum of Fig. 3 and data of Table 1. Acetamide and methyl groups of CNCbl were omitted for clarity. 
Table 1 Summary of product ions obtained by MALDI MS/MS at m/z 1619 in positive ion mode using CCICA as a matrix (see Fig. 3 and Scheme 1 )

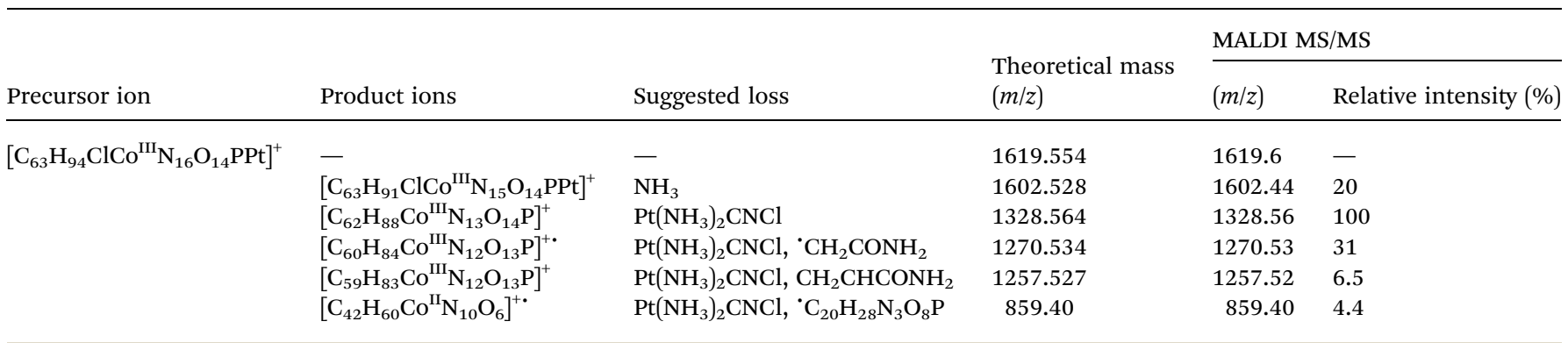

at $m / z 1328.57$, i.e., a peak whose $m / z$ value is 1 unit lower than the main product ion obtained in tandem MS of intact protonated $\mathrm{CNCbl}$ at $\mathrm{m} / \mathrm{z} 1355 .{ }^{26}$ Other relatively intense peaks were recorded at $\mathrm{m} / z 1602.44,1270.54,1257.53$ and 859.40. The isotopic cluster at $\mathrm{m} / \mathrm{z} 1602$ is most likely due to a positively charged species formed upon the loss of a neutral ammine ligand from the CNCbl-monochloro cisplatin conjugate, as illustrated in Scheme 1. In the same scheme is depicted the proposed structure of the product ion at $m / z 1328$, in which cobalamin lost the $\mathrm{CN}^{-}$ligand bound to $\mathrm{Co}$ (III) and the $\mathrm{Pt}$ (II) moiety. The assignment of all the peaks shown in Fig. 3 is summarized in Table 1; the second and fourth columns of this table show the chemical composition for each product ion and the expected (theoretical) $\mathrm{m} / \mathrm{z}$ value, while the third column reports the suggested neutral losses. The last two columns summarize the experimental results, namely the measured $\mathrm{m} / \mathrm{z}$ values and the relative intensity of product ions.

\subsection{MALDI MS of the CNCbl-Pt ${ }^{\mathrm{II}}(R, R$-DACH) conjugate}

The formation of the CNCbl-oxaliplatin conjugate has not been explored yet. Although cisplatin is the best-known chemotherapy drug, oxaliplatin is the most recent platinum anticancer drug to have gained international approval for marketing and clinical use. ${ }^{10}$ This drug is now a component of the front-line combination of clinical chemotherapy treatment for colon cancer. ${ }^{5}$ Oxaliplatin features a chelating oxalate leaving group ligand and a chelating $R, R$-DACH non-leaving ligand that has long been investigated as component in platinum anticancer agents. $^{30,31}$ Empirical evidence revealed that the $R, R$

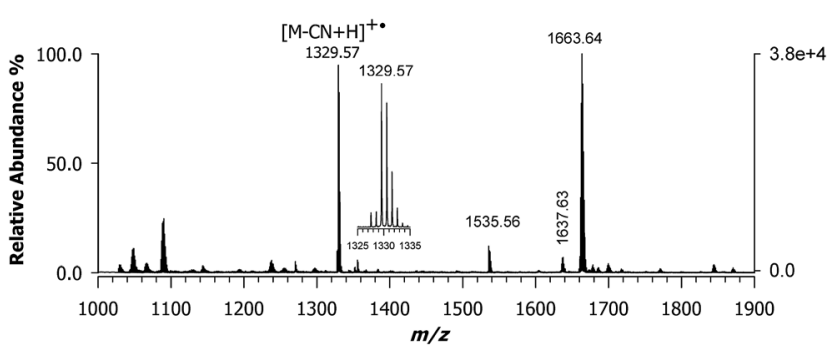

Fig. 4 MALDI-ToF mass spectrum using CCICA matrix of the conjugate formed between $\mathrm{CNCbl}$ and oxaliplatin that features a chelating $R, R$-diaminocyclohexane $(R, R$-DACH) non-leaving group ligand ( $[\mathrm{M}+$ $\left.\left.\mathrm{Pt}^{\prime \prime}(R, R-\mathrm{DACH})\right]^{+}\right)$with the most intense peak of the ion cluster at $\mathrm{m} / \mathrm{z}$ 1663.64. Its isotopic pattern is compared in Fig. 5 (plot D) with two theoretical profiles. stereoisomer was more effective than the $S, S$ enantiomer or the related meso compound with cis amine groups. This difference was revealed by crystallographic studies that showed how the $R, R$ isomer preferentially forms a hydrogen bond between a pseudo equatorial $\mathrm{N}-\mathrm{H}$ hydrogen atom of the $R, R-\mathrm{DACH}$ ligand. ${ }^{32}$ Since it is common the use of oxaliplatin in human cancer treatment, we wished to evaluate if a conjugate with CNCbl could be formed under the same experimental conditions adopted to react cisplatin. Considering that the oxalato ligand has a strong chelating effect on Pt(II), it must be substituted for ensuring the coordination with the cyano group of CNCbl. For this reason, we used the cis-sulfoa quo $R, R$-DACH$\mathrm{Pt}(\mathrm{II})$ complex. The MALDI MS spectrum of the reacted mixture
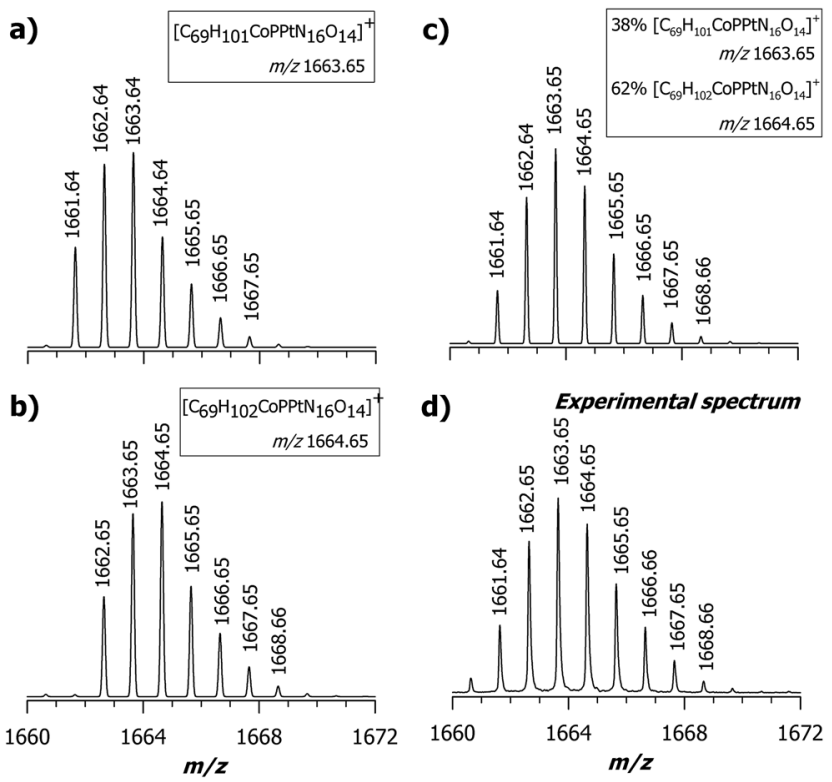

Fig. 5 Comparison between calculated ( $a, b$ and $c)$ and measured MS spectra (d) for the adduct $\left[\mathrm{M}+\mathrm{Pt}^{\prime \prime}(R, R-\mathrm{DACH})\right]^{+}$; (a) theoretical isotopic pattern calculated with the following empirical formula $\left[\mathrm{C}_{69} \mathrm{H}_{101} \mathrm{Co}^{1 ! \prime} \mathrm{N}_{16} \mathrm{O}_{14} \mathrm{PPt}^{\prime \prime}\right]^{+}$in which the most intense peak is at $\mathrm{m} / \mathrm{z}$ 1663.64. (b) Theoretical isotopic pattern of $\left[\mathrm{C}_{69} \mathrm{H}_{102} \mathrm{Co}^{\text {III }} \mathrm{N}_{16} \mathrm{O}_{14} \mathrm{PPt}\right]^{\text {II }}{ }^{+}$ in which the most intense peak is at $\mathrm{m} / z$ 1664.65. (c) Combined spectrum obtained summing up $38 \%$ of $\left[\mathrm{C}_{69} \mathrm{H}_{101} \mathrm{Co}^{\prime \prime \prime} \mathrm{N}_{16} \mathrm{O}_{14} \mathrm{PPt}\right]^{+}$and $62 \%$ of $\left[\mathrm{C}_{69} \mathrm{H}_{102} \mathrm{Co}^{\prime \prime \prime} \mathrm{N}_{16} \mathrm{O}_{14} \mathrm{PPt}^{\prime \prime}\right]^{+}$which seems in close agreement with the measured one (d); it represents the expanded view of Fig. 4 in the range $1660-1672 \mathrm{~m} / \mathrm{z}$. All calculated spectra were obtained by the Xcalibur software 2.2 (Thermo Scientific) using a resolution of 15.000 (FWHM). 
is shown in Fig. 4; of course, the matrix used was CClCA. As expected, a very intense isotopic cluster was observed with the most intense signal at $m / z 1663.64\left(\left[\mathrm{M}+\mathrm{Pt}^{\mathrm{II}}(R, R-\mathrm{DACH})\right]^{+}\right)$as confirmed on the basis of its isotope peak pattern (see below for further description of isotope peaks) along with a peak at $\mathrm{m} / \mathrm{z}$ 1329.57 identified as decyanated and protonated CNCbl ([M $\mathrm{CN}+\mathrm{H}^{+\bullet}$ ). No presence of doubly-charged ions was evidenced.

A critical issue in these experiments is the extent of the chemical reaction. In the mass spectrum, at any point sampled in time after at least $2 \mathrm{~h}$, there is generally a second major peak detected at $m / z$ 1329.57, as shown in Fig. 4. A complete set of MALDI MS spectra of samples reacted at $0,2,4,8$, and $16 \mathrm{~h}$ is reported in the ESI, Fig. $\mathrm{S} 2 . \dagger$ Since in this case $\mathrm{Pt}$ (II) is chelated by a non-leaving group along with the cis-sulfoa quo ion, these last two ligands can be easily replaced. Our next step was to carefully examine the ion cluster at $\mathrm{m} / \mathrm{z}$ 1663.64. When a comparison was made between calculated and measured MALDI MS spectra, an odd inconsistency was noted. The calculated isotopic pattern using the following chemical formula $\left[\mathrm{C}_{69} \mathrm{H}_{101} \mathrm{Co}^{\mathrm{III}} \mathrm{N}_{16} \mathrm{O}_{14} \mathrm{PPt}^{\mathrm{II}}\right]^{+}$, which exhibits the most intense peak at $m / z 1663.64$, is given in plot (a) of Fig. 5. The isotopic cluster profile with the most intense seven peaks starting at $\mathbf{1 6 6 1 . 6 4}$ does not match the measured one reported in plot (d) of the same figure. A second attempt with a chemical formula containing and additional hydrogen (i.e.,
$\left.\left[\mathrm{C}_{69} \mathrm{H}_{102} \mathrm{Co}^{\mathrm{III}} \mathrm{N}_{16} \mathrm{O}_{14} \mathrm{PPt}^{\mathrm{II}}\right]^{+}\right)$in which the most intense peak is at $\mathrm{m} / \mathrm{z} 1664.65$ also failed, as in this case the monoisotopic mass of the first isotopic-pattern peak is at $m / z$ 1662.65. A possible explanation is that the experimental spectrum is due to a combination of two chemical species (see Scheme 2), as illustrated in plot (c) of Fig. 5 obtained by summing up the empirical formula of 2 and 3 , namely $\left[\mathrm{C}_{69} \mathrm{H}_{101} \mathrm{Co}^{\mathrm{III}} \mathrm{N}_{16} \mathrm{O}_{14} \mathrm{PPt}^{\mathrm{II}}\right]^{+}$ and $\left[\mathrm{C}_{69} \mathrm{H}_{102} \mathrm{Co}^{\mathrm{III}} \mathrm{N}_{16} \mathrm{O}_{14} \mathrm{PPt}^{\mathrm{II}}\right]^{+\cdot}$ at a ratio of $c a .0 .60: 1.0$. The combined spectrum seems in close agreement with the measured ion cluster and additional support to this suggestion will be supplied in the next paragraph.

\subsection{MALDI MS/MS of the CNCbl-Pt ${ }^{\mathrm{II}}(R, R$-DACH) conjugate}

From the data discussed above, the presence of two different empirical formulae of $\mathrm{CNCbl}+\mathrm{Pt}^{\mathrm{II}}(R, R-\mathrm{DACH})$ conjugates comes out and there is the need to verify the correctness and reliability of such a hypothesis. Fig. 6 shows the MALDI MS/MS spectrum of the precursor ion at $\mathrm{m} / \mathrm{z}$ 1663. Two most intense peaks can be seen at $m / z 1605.57$ and 1270.54 . Examination of peaks at $m / z 1605.57,1549.59,1517.57$ and 1305.54 indicate the occurrence of platinum isotopes, that agrees with the most abundant natural isotopes of Pt (i.e., 194 as relative molar mass and $32.86 \%$ relative abundance, 195 with $33.78 \%, 196$ with $25.21 \%$ and 198 with $7.36 \%$ (ref. 33)) as evidenced both in terms

A)
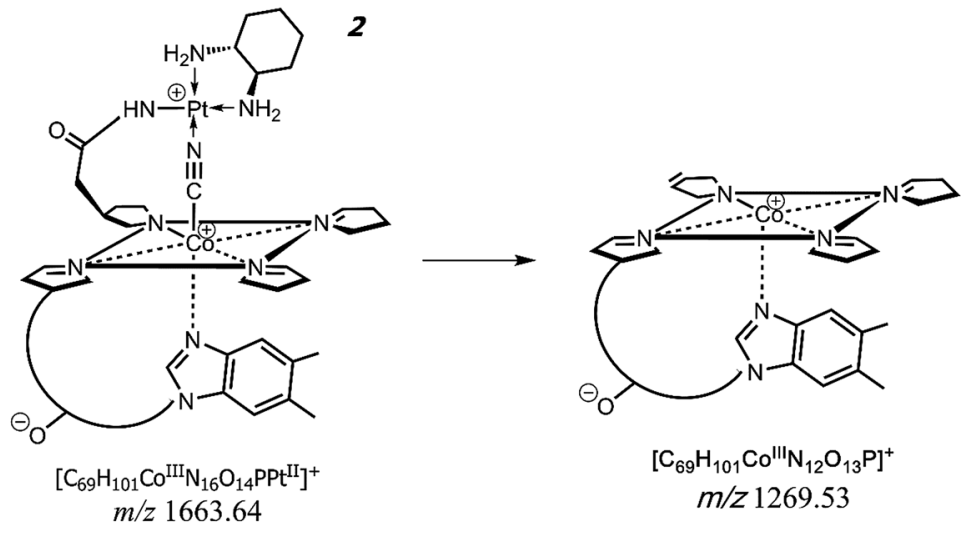

B)
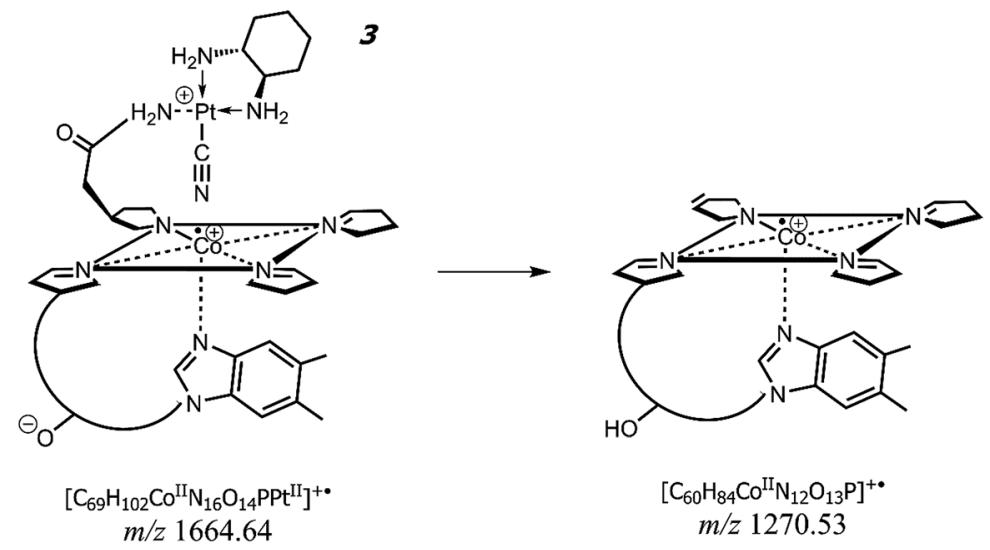

Scheme 2 Proposed formation of product ions at $\mathrm{m} / \mathrm{z} 1269.53$ and 1270.53 from the precursor ions at $\mathrm{m} / \mathrm{z} 1663.64$ (compound 2 ) and 1664.64 (compound 3), respectively. See MALDI MS/MS spectrum of Fig. 6 and data of Table 2. Both compounds (2) and (3) are depicted in their schematic view. 


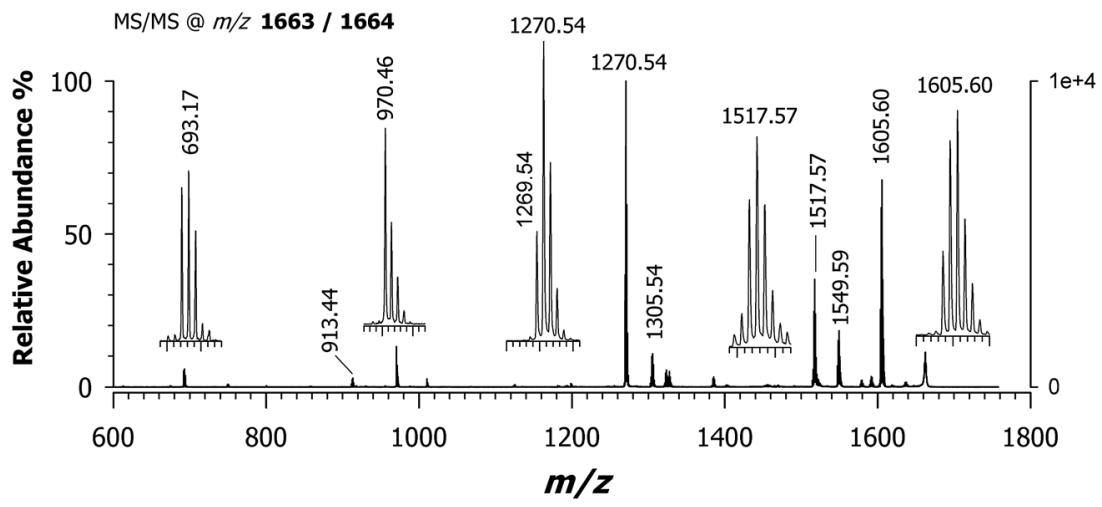

Fig. $6 \mathrm{MALDI}-\mathrm{ToF} / T o F$ tandem mass spectrum in positive ion mode of $\left[\mathrm{M}+\mathrm{Pt}^{\prime \prime}(R, R-\mathrm{DACH})\right]^{+}$at $\mathrm{m} / \mathrm{z}$ 1663/1664 using CClCA matrix; all product ions are identified in Table 2. Note the dominant peak in the spectrum is at $m / z 1270.54\left(\left[\mathrm{C}_{60} \mathrm{H}_{84} \mathrm{Co}^{\prime \prime} \mathrm{N}_{12} \mathrm{O}_{13} \mathrm{P}\right]^{+\cdot}\right)$ and the occurrence of a peak at $\mathrm{m} / \mathrm{z} 1269.54\left(\left[\mathrm{C}_{60} \mathrm{H}_{83} \mathrm{Co}^{I ! I} \mathrm{~N}_{12} \mathrm{O}_{13} \mathrm{P}\right]^{+}\right)$. The empirical formula and suggested structures of both ions are depicted in Scheme 2.

of isotopic pattern (see expanded view in the inset) and rational formula of the corresponding positively-charged ions. More importantly, the expanded window of the signal around $\mathrm{m} / \mathrm{z}$ 1270 reveals the absence of $\mathrm{Pt}$ in the corresponding empirical formula (i.e., $\left[\mathrm{C}_{60} \mathrm{H}_{84} \mathrm{Co}^{\mathrm{II}} \mathrm{N}_{12} \mathrm{O}_{13} \mathrm{P}\right]^{+\cdot}$ ) and a monoisotopic peak at $\mathrm{m} / z$ 1269.54. This product ion takes the form of $\left[\mathrm{C}_{60} \mathrm{H}_{83^{-}}\right.$ $\left.\mathrm{Co}^{\mathrm{III}} \mathrm{N}_{12} \mathrm{O}_{13} \mathrm{P}\right]^{+}$. All these data are summarized in Table 2, where all product ions are listed in terms of chemical formula with the oxidation number of cobalt ion in the corrin ring. Having already eliminated the possibility of double-charge product ions we were left with only one conclusion and that is a CNCbl bridged with the $\mathrm{CN}$ group between $\mathrm{Co}$ (III) (or $\mathrm{Co}(\mathrm{II})$ ) and $\mathrm{Pt}(\mathrm{II})$ ion of $R, R$-DACH. The identity of the peaks arising at $\mathrm{m} / \mathrm{z}$ 1269.53 and 1270.53 is overviewed in Scheme 2, showing their suggested formation from precursor ions at $\mathrm{m} / \mathrm{z} 1663.64,2$, and 1664.64, 3, respectively. Accordingly, these two chemical-species are similar in the chemical composition (formally differing in the content of one $\mathrm{H}$ ) but very different in their chemical structures. The most striking difference is that the suggested structure of ion at $m / z 1663$ (i.e., $\left[\mathrm{C}_{69} \mathrm{H}_{101} \mathrm{Co}^{\mathrm{III}} \mathrm{N}_{16} \mathrm{O}_{14} \mathrm{PPt}^{\mathrm{II}}\right]^{+}$) features a $\mathrm{CN}$ bridge like $\mathrm{Co}(\mathrm{III})-\mathrm{CN}-\mathrm{Pt}(\mathrm{II})$, as mentioned before, and an acetamide bridging arm (i.e., acetamide arm a, c, or $\mathrm{g})^{26}$ covalently bound to $\mathrm{Pt}^{\mathrm{II}}\left(R, R\right.$-DACH) (i.e., $-\mathrm{CH}_{2} \mathrm{CO}-\mathrm{HN}-\mathrm{Pt}^{\mathrm{II}}(R, R$ $\mathrm{DACH})$ ). Even though the propionamide arms b, $\mathrm{d}$ and e are longer, their stereochemical configuration on the lower side of the corrin rings do not seemingly allow coordination with the platinum complex as an excessive structure distortion would take place. Notably, compound 3 at $m / z 1664.64$ (i.e., $\left[\mathrm{C}_{69} \mathrm{H}_{102^{-}}\right.$ $\left.\mathrm{Co}^{\mathrm{II}} \mathrm{N}_{16} \mathrm{O}_{14} \mathrm{PPt}^{\mathrm{II}}\right]^{+*}$ ) is a radical cation with a reduced form of cobalt (i.e., $\mathrm{Co}^{\mathrm{II}}$ ) yielding an unpaired electron. The most important feature of this ion is that the $\mathrm{CN}$ group is now covalently linked to the positively charged Pt(II) of DACH (see Scheme 2B). This interpretation would explain the formation of two chemically different conjugates between $\mathrm{CNCbl}$ and $\mathrm{Pt}^{\mathrm{II}}(R, R-\mathrm{DACH})$.

As illustrated in Fig. 7, the MALDI-ToF mass spectrum of the $\mathrm{CNCbl}-\mathrm{Pt}^{\mathrm{II}}\left(R, R\right.$-DACH) sample after $16 \mathrm{~h}$ of reaction at $60{ }^{\circ} \mathrm{C}$, with CHCA as MALDI matrix, affords the decyanated/ deprotonated $\mathrm{CNCbl}$ molecule as the most abundant peak, followed by the ones at $\mathrm{m} / z 1664.65$ and 1637.64. Owing to the mass shift of 27 units the peak at $\mathrm{m} / z 1637.64$ could be formally assigned to an ion cluster in which there is the loss of neutral

Table 2 Summary of product ions obtained by MALDI MS/MS at m/z 1663 and 1664 in positive ion mode using CCICA as matrix (see Fig. 6 and Scheme 2)

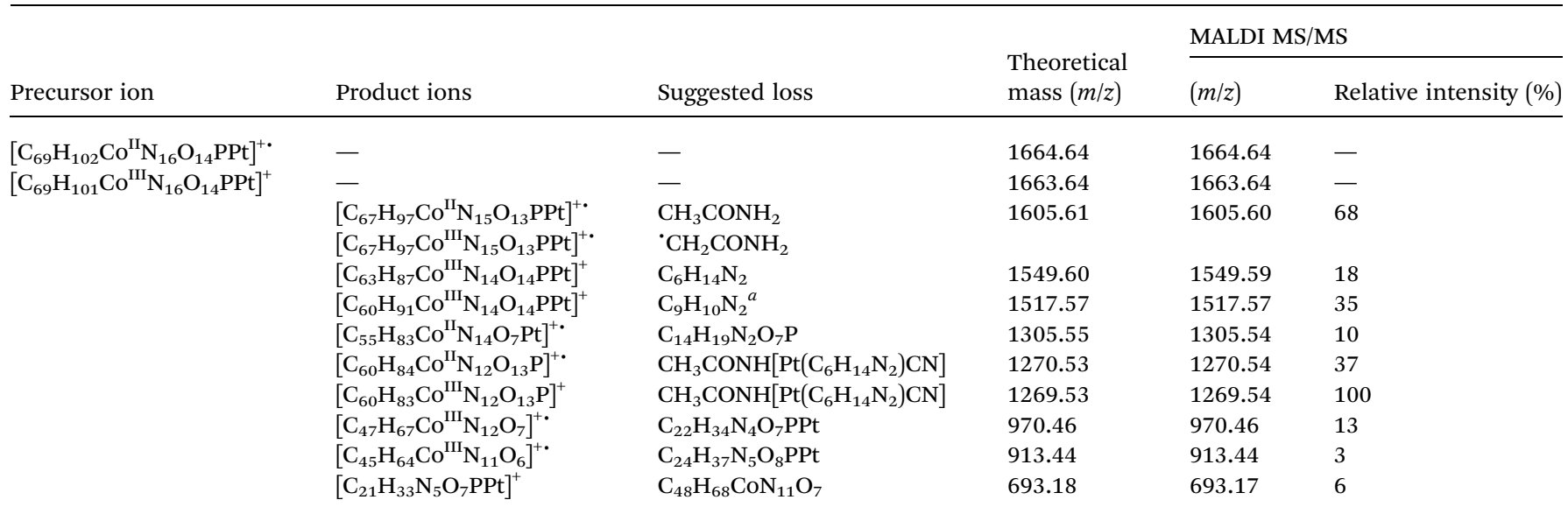

${ }^{a}$ Loss of 5,6-dimethylbenzimidazole. 


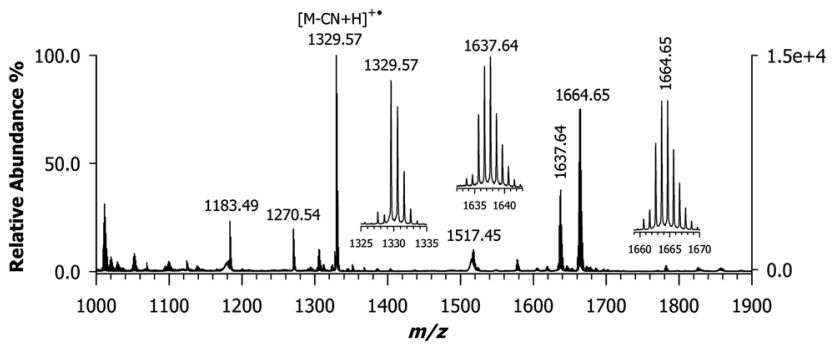

Fig. 7 MALDI-ToF mass spectrum using CHCA matrix of the conjugate formed between $\mathrm{CNCbl}$ and oxaliplatin $\left(\left[\mathrm{M}+\mathrm{Pt}^{\prime \prime}(R, R-\mathrm{DACH})\right]^{+}\right)$. On the right is given the enlarged isotopic pattern of the ion cluster at $\mathrm{m} / \mathrm{z}$ 1664.65. See text for details.

HCN from the ion at 1664.64 (compare Fig. 4 and 7). As already mentioned, the application of CHCA was generally found to give poor spectra as demonstrated for CNCbl, most likely because of the very weak $\mathrm{Co}$ (III)-CN bond. However, in the present case the second most intense peak was found at $\mathrm{m} / \mathrm{z}$ 1664.65, which seems to be compound 3 depicted in Scheme 2 (see also expanded view in the inset of Fig. 7). Although MALDI is a very soft ionization process, fragmentation occurs and leads to HCN release yielding what is presumably a species formed in the gasphase. For comparison, Fig. S3 of ESI $\dagger$ shows the evolution observed for the same sample reported in Fig. S2, $\dagger$ but in this case CHCA was used as matrix. With this MALDI matrix, the peak at $\mathrm{m} / \mathrm{z} 1664.63$ grows steadily up to $8 \mathrm{~h}$. However, an intense peak at $m / z 1637.64$ is always present, being formally equivalent to the loss of $\mathrm{HCN}$ in the gas phase $[(\mathrm{CNCbl}+$ $\mathrm{Pt}^{\mathrm{II}}(R, R$-DACH $\left.\left.)-\mathrm{HCN}\right)\right]^{+}$, thus signifying the very labile $\mathrm{Co}-\mathrm{CN}$ bond. Beyond technical details, a thorough chemical characterization by MALDI MS can be obtained whatever the Pt(II) drug conjugate formed with $\mathrm{CNCbl} .^{17}$

\section{Conclusions}

Using an uncommon MALDI matrix (i.e., CClCA) mainly proposed for proteomics, the present study has highlighted the effectiveness of MALDI MS for the characterization, at a molecular level, of conjugates formed by cyanocobalamin and anticancer platinum(II) complexes. While cisplatin gives rise to a single conjugate that affords a $\mathrm{CN}$ bridge between $\mathrm{Co}$ (III) and $\mathrm{Pt}(\mathrm{II})$, in the case of a $R, R$-DACH non-leaving group two different compounds were obtained based on data inferred through tandem MS experiments. We anticipate that the use of MALDI MS in combination with CClCA matrix will help to investigate platinum-based agents of next generation and their conjugates with targeting molecules with potential use as prodrugs for cancer therapy. Moreover, it can be very useful to investigate tissue uptake CNCbl-platinum anticancer agents by tissue imaging MALDI-MS.

\section{Conflicts of interest}

The authors have declared no conflicts of interest.

\section{Acknowledgements}

This work was supported by the project PONa3_00395/1 "BIOSCIENZE \& SALUTE (B\&H)" of Italian Ministero per l'Istruzione, l'Università e la Ricerca (MIUR). The authors acknowledge with thanks A. Panella and F. Greco for their assistance in the preparation of some samples. The authors also thank the University of Bari and Consorzio Interuniversitario di Ricerca in Chimica dei Metalli nei Sistemi Biologici (CIRCMSB).

\section{References}

1 S. J. Berner-Price and T. G. Appleton, in Platinum-Based Drugs in Cancer Therapy, Humana Press, 2000, pp. 3-35.

2 B. Lippert, in Cisplatin: Chemistry and Biochemistry of a Leading Anticancer Drug, ed. B. Lippert, Verlag Helvetica Chimica Acta, Zürich, 2006, pp. 377-403.

3 L. R. Kelland, in Cisplatin: Chemistry and Biochemistry of a Leading Anticancer Drug, ed. B. Lippert, Verlag Helvetica Chimica Acta, Zürich, 2006, pp. 497-521.

4 A. Pelmenschikov, I. Zilberberg, J. Leszczynski, A. Famulari, M. Sironi and M. Raimondi, Chem. Phys. Lett., 1999, 314, 496-500.

5 L. Kelland, Nat. Rev. Cancer, 2007, 7, 573-584.

6 S. Dhar, F. X. Gu, R. Langer, O. C. Farokhzad and S. J. Lippard, Proc. Natl. Acad. Sci. U. S. A., 2008, 105, 17356-17361.

7 T. C. Johnstone, K. Suntharalingam and S. J. Lippard, Chem. Rev., 2016, 116, 3436-3486.

8 T. Alcindor and N. Beauger, Curr. Oncol., 2011, 18, 18-25.

9 R. Mehmood, R. K. Mehmood, J. Parker, S. Ahmed, E. Qasem, A. A. Mohammed, M. Zeeshan and E. Jehangir, World J. Oncol., 2014, 5, 97-108.

10 J. Graham, M. Muhsin and P. Kirkpatrick, Nat. Rev. Drug Discovery, 2004, 3, 11-12.

11 S. H. van Rijt and P. J. Sadler, Drug Discovery Today, 2009, 14, 1089-1097.

12 C. Rovira, K. Kunc, J. Hurter and M. Parrinello, Inorg. Chem., 2001, 40, 11-17.

13 K. L. Brown, Chem. Rev., 2005, 105, 2075-2149.

14 G. Russell-Jones, K. McTavish, J. McEwan, J. Rice and D. Nowotnik, J. Inorg. Biochem., 2004, 98, 1625-1633.

15 M. T. Q. Tran, S. Stürup, I. H. Lambert, B. Gammelgaard, E. Furger and R. Alberto, Metallomics, 2016, 8, 298-304.

16 A. Pettenuzzo, R. Pigot and L. Ronconi, Eur. J. Inorg. Chem., 2017, 2017, 1625-1638.

17 H. S. Oberoi, N. V. Nukolova, A. V. Kabanov and T. K. Bronich, Adv. Drug Delivery Rev., 2013, 65, 16671685.

18 S. M. Clardy, D. G. Allis, T. J. Fairchild and R. P. Doyle, Expert Opin. Drug Delivery, 2011, 8, 127-140.

19 S. Mundwiler, B. Spingler, P. Kurz, S. Kunze and R. Alberto, Chem.-Eur. J., 2005, 11, 4089-4095.

20 P. Ruiz-Sánchez, S. Mundwiler, B. Spingler, N. R. Buan, J. C. Escalante-Semerena and R. Alberto, J. Biol. Inorg. Chem., 2008, 13, 335-347. 
21 R. Waibel, H. Treichler, N. G. Schaefer, D. R. Van Staveren, S. Mundwiler, S. Kunze, M. Ku, R. Alberto and J. Nu, Cancer Res., 2008, 68, 2904-2911.

22 P. Ruiz-Sánchez, C. König, S. Ferrari and R. Alberto, J. Biol. Inorg. Chem., 2011, 16, 33-44.

23 M. Hossain and P. A. Limbach, in Electrospray and MALDI Mass Spectrometry: Fundamentals, Instrumentation, Practicalities, and Biological Applications: Second Edition, John Wiley \& Sons, Inc., Hoboken, NJ, USA, 2012, pp. 215244.

24 L. He, G. Wei and K. K. Murray, J. Am. Soc. Mass Spectrom., 1997, 8, 140-147.

25 Y.-T. Chen and Y.-C. Ling, J. Mass Spectrom., 2002, 37, 716730.

26 C. D. Calvano, G. Ventura, F. Palmisano and T. R. I. Cataldi, J. Mass Spectrom., 2016, 51, 841-848.
27 J. Bianga, A. Bouslimani, N. Bec, F. Quenet, S. Mounicou, J. Szpunar, B. Bouyssiere, R. Lobinski and C. Larroque, Metallomics, 2014, 6, 1382-1386.

28 X. Liu and A. B. Hummon, Sci. Rep., 2016, 6, 385073-385080. 29 C. D. Calvano, G. Ventura, M. Trotta, G. Bianco, T. R. I. Cataldi and F. Palmisano, J. Am. Soc. Mass Spectrom., 2017, 28, 125-135.

30 Y. Kidani, M. Noji and T. Tashiro, Gan, 1980, 71, 637-643.

31 T. C. Johnstone, Polyhedron, 2014, 67, 429-435.

32 B. Spingler, D. A. Whittington and S. J. Lippard, Inorg. Chem., 2001, 40, 5596-5602.

33 J. Meija, T. B. Coplen, M. Berglund, W. A. Brand, P. De Bièvre, M. Gröning, N. E. Holden, J. Irrgeher, R. D. Loss, T. Walczyk and T. Prohaska, Pure Appl. Chem., 2016, 88, 293-306. 